\title{
Work related injuries and musculoskeletal disorders among child workers in the brick kilns of Nepal
}

\begin{abstract}
:
Brick manufacturing is a labor intensive informal industry using child workers as the major work force in Nepal. Workers are required to use physical strength, carry heavy loads and remain in a squatted posture for longer periods doing repetitive tasks posing threats to musculoskeletal system. This study involved cross sectional study of children aged 17 years and below. The study respondent included 101 cases and 64 controls in Bhaktapur and 97 cases and 43 controls in Sarlahi. Lack of adequate physical infrastructures, poor working conditions with non existent safety procedures have posed risk to physical, metal and overall well being of children. The study identifies work related physical ailments and discomforts dominate brick industries of Nepal. The musculoskeletal disorder related pain and discomfort was experienced by 73 per cent of working children in Bhaktapur and 58 per cent in Sarlahi. The odds ratio suggests that working children were 8 times more likely to experience trouble or body pain compared to non-working children. This study finds that presence of inferior physical environment, working conditions and practices has contributed to musculoskeletal injuries and problems exposing working children to risks and hazards.
\end{abstract}

Key Words: Brick; child worker; ergonomics; musculoskeletal disorder; Nepal

\section{Introduction}

Brick manufacturing is a labor intensive informal industry of Nepal employing children as major workforce. This unorganized sector is growing multifold due to ever increasing demands of brick for continued urban and rural expansions. Despite of engagement of large population in brick industries data on number of employed workers, accidents, health and safety issues are missing.

Brick making is a painstaking labor job often performed by families accompanied by children living in temporary settlements called Jhyauli. The brick making mostly involves repetitive works including soil excavation and kneading, molding and staking, drying and transport of green and dry bricks. Previous studies have identified causal relationship between highly repetitive work and neck and neck/shoulder musculoskeletal disorders [1]. The repetitive works involving continuous arm or hand movements affects neck/shoulder musculature and generate loads on the neck/shoulder area [1].

The seasonal brick work starting from September/October usually ends before arrival of the monsoons (June-July). Conditions are fair enough to work outside until the mid of February while later months are treacherous with scorching heat.
Sunil Kumar Joshi', Pranab Dahal ${ }^{2}$, Agya Poudel $^{3}$, Helen Sherpa ${ }^{4}$

${ }^{1}$ Department of Community Medicine, Kathmandu Medical College, Sinamangal

${ }^{2}$ Development Sociologist and Occupational Health Researcher, ECO Trans Consult

${ }^{3}$ Monitoring and Evaluation Officer, WEI Nepal

${ }^{4}$ Country Director, WEI Nepal

Corresponding Author:

Dr.Sunil Kumar Joshi, Email: drsunilkj@gmail.com

(c) 2013 IJOSH All rights reserved. DOI: http://dx.doi.org/10.3126/ijosh.v3i2.10271
The brick making process takes place in dry conditions with exposure to clay dust, sand, and fumes from machines and smoke from furnace. The exposure to dust occurs during excavation of soil, molding of clay and transportation of baked bricks. Fine carbon particulate matter is also released during coal crushing process used for fuelling furnace. The dust and suspended particles blown by air also includes as source of dust. The height of chimney however bars dispersion of smoke at ground level, but fine soot and other particulate matter gets dispersed in the vicinity. The wind at times also carries smoke from adjacent kilns exposing worker with smoke and soot particles.

The brick kilns may emit fine dust particles, hydrocarbons, Sulphur Dioxide $\left(\mathrm{SO}_{2}\right)$, Oxides of Nitrogen $\left(\mathrm{NO}_{\times}\right)$, Fluoride compounds, Carbon Monoxide (CO) and some amount of carcinogenic dioxins if rubber tyres were used as fuel. Published studies demonstrate that inhalation of these matters could affect lung function and lead to increased cardiovascular and respiratory diseases. High level of carbon monoxide produced in brick kilns due to poor design could also increase incidence of heart disease. Previous studies have found the evidence of increase in rate of bronchitis, asthma, impaired lung function, pharyngitis, cough, eye irritation, fibrosis, emphysema, allergic rhinitis, low birth weight associated with deteriorating 
ambient air quality [3 - 7].

In addition to above mentioned health effects, musculoskeletal outcomes are also of concern in our context. Brick manufacturing is a labor intensive industry requiring muscular energy at most of its production stages. Workers are required to carry heavy loads, well above recommended limit and remain in squatted posture for long periods doing repetitive tasks posing threats to musculoskeletal system. The risks to children are more hazardous due to their growing bodies and weaker systems compared to the adults. Work related musculoskeletal disorders (WMSDs) are common in workers in brick manufacturing industries involved in sorting and stacking processes. They not only cause human injuries and suffering but also involve economic cost reducing working capacity and lesser production [8]. The processes in brick kilns involve interaction of various factors; personal factors include fatigue, fitness, age, experience of the workers while circumstantial factors involve work schedule and work load and lastly psychological support among workers contributes to affect work and working life [9].

A recent report on hazardous work in brick kiln industries in Nepal identified ergonomics as an occupational safety and health issue. The report stated that the main risk factors involve unorganized work procedures, equipment, and workstation design leading to incorrect body posture that can affect joints and muscles. Repetitive tasks requiring frequent bending or twisting of the wrists, knees, hips, or shoulders may impose increased stress on the joints [10]. Very few studies have been published on musculoskeletal problems and ergonomics in the workers in brick kilns and among child workers [11,12]. A cross-sectional study conducted by Manoharan et al. among 264 brick kiln workers in India revealed that workers suffered from multiple musculoskeletal problems that impaired their daily lives. A study in India examined brick loads and work-related health effects among teenage girls working in brick kilns and reported 86 percent of participants suffered from work-related pain in different body parts, and the main risk factors identified were awkward position at work [12]. Long term exposure to awkward postures further increases risks of injury. Absence of personal protective equipment makes workers more vulnerable also to injury associated with material handling [13].

This study shades lights on safety and health issues and ergonomics in the selected brick kilns of Nepal focusing more on child workers. The objective of this part of the study was to study prevalence of musculoskeletal disorders and injuries among child workers in the selected brick kilns in Nepal.

\section{Methods}

This study is a cross sectional study design involving children 17 years and below of age working at brick kilns in Bhaktapur and Sarlahi districts. A multi stage stratified sampling method was adapted to select children required for the study. At first stage of the sampling, two districts were selected based on the information and identification of district categories i.e. worst and best as well as representative of Hill and Terai. Bhaktapur was selected as a best district and Sarlahi as a worst based on classification by National Population Census 2001 [14]. In second stage, village development committees (VDC) having brick factories were selected using probability proportional to size.

A previous study conducted in different parts of the country showed that health problems among child laborers were 37 per cent [15]. Therefore, the sample size required $(n=90)$ was calculated according to expected percentage of health problems of 37 per cent with a precision of 10 per cent and a confidence level of 95 per cent. Hence, 101 child labors were selected from Bhaktapur district and 97 from Sarlahi district for this study. Children working in the brick kilns were defined as cases for this study.

The selection of controls i.e. non-working children was very difficult due to equivalent characteristics in terms of socio-economic status, ethnicity, migration and parental occupation. Thus, the control group was selected using purposive sampling techniques. Only those non-working children meeting the criteria were selected as comparison group. So, 64 non-working children from Bhaktapur and 43 from Sarlahi districts were selected as the comparison group.

Standardized Nordic questionnaires for the analysis of musculoskeletal symptoms [16] and questions on injuries were administered for collecting primary quantitative data on musculoskeletal disorders. Data collection for the study was conducted during March and April 2013.

\section{Results}

The brick making job was found to be more mechanized in the kilns of Bhaktapur with excavators and motorized soil kneading machines compared to manual practices in Sarlahi. The transportation of kneaded soil for molding also used wheel barrows in Bhaktapur showing better working process compared to Sarlahi where workers lifted heavy loads in head. A general overview on working process shows kilns of Bhaktapur relying more on recent mechanized trends and practices compared to conventional practices at Sarlahi.

The working environment also plays a crucial role in determining wellbeing of the workers. Kilns at both the districts were in operation in an open area with no shades and covers exposing workers to heat, dust and external conditions. The basic sanitation and hygiene practices were nonexistent with complete lack of safe toilets and drinking water. Only one of sampled kiln in Bhaktapur had make-shift-toilet constructed for workers while in other sampled kilns, workers were found to be using open areas as toilets.

The risks of fall in the sampled kilns were found to be high exposing children to musculoskeletal injuries. Three major areas were identified with higher fall risks, firstly, the non-fenced pit formed after soil excavation posed considerable risk. Secondly, 
soil kneading areas rested on temporary structures in Bhaktapur posed risk of toppling and fall. Lastly, transportations of green and dried brick to and fro from furnace on a narrow wooden pane pose risk of human and object fall.

The total respondent size in Bhaktapur was 165 with 101 cases and 64 controls. The cases comprised of 62 males and 39 females, while the control group had 27 males and 37 females. The total respondents percentage based on sex was observed to be 54 per cent male and 46 per cent female respectively. The total respondent size in Sarlahi was 140 with 97 cases and 43 controls. The cases comprised of 26 males and 71 females, while the control group had 19males and 24 females. The total respondents percentage based on sex was observed to be 32.14 per cent male and 67.86 per cent female respectively. The table I below shows the demography and age distribution of samples for this study.

\section{Table I Demography and age distribution of sample}

\begin{tabular}{|c|c|c|c|c|}
\hline \multirow{2}{*}{ Variables } & \multicolumn{2}{|c|}{ Bhaktapur District } & \multicolumn{2}{c|}{ Sarlahi District } \\
\cline { 2 - 5 } & $\begin{array}{c}\text { Case } \\
(\mathrm{N}=101)\end{array}$ & $\begin{array}{c}\text { Control } \\
(\mathrm{N}=64)\end{array}$ & $\begin{array}{c}\text { Case } \\
(\mathrm{N}=97)\end{array}$ & $\begin{array}{c}\text { Control } \\
(\mathrm{N}=43)\end{array}$ \\
\cline { 2 - 5 } & Number (\%) & $\begin{array}{c}\text { Number } \\
(\%)\end{array}$ & $\begin{array}{c}\text { Number } \\
(\%)\end{array}$ & $\begin{array}{c}\text { Number } \\
(\%)\end{array}$ \\
\hline Sex & $62(61.4)$ & $27(42.2)$ & $26(26.8)$ & $19(44.2)$ \\
\hline Male & $39(38.6)$ & $37(57.8)$ & $71(73.2)$ & $24(55.8)$ \\
\hline Female & $21(20.8)$ & $4(6.2)$ & $14(14.4)$ & $1(2.3)$ \\
\hline Age (Years) & $38(37.6)$ & $44(68.8)$ & $53(54.6)$ & $22(51.2)$ \\
\hline Under 10 & $42(41.6)$ & $16(25)$ & $30(30.9)$ & $20(46.5)$ \\
\hline $10-14$ & $15-17$ & & & \\
\hline
\end{tabular}

The injury history comparison as shown in table II among case and control groups indicated that working children had more susceptibility and exposure to injuries compared to non-working children. It was observed that 41.6 per cent of working children in Bhaktapur reported to have injuries compared to 29.7 per cent in non-working children in past one year. It was identified that occupation related injuries in children majorly affected upper and lower limbs. Most of the working children were found to be seasonal labors with engagement to various informal sectors over a year not limiting to agriculture, transport, construction and manual labors increasing more vulnerabilities to injuries.

The injuries sustained by control group (non-working children) were mostly attributed to play and house hold works. It was found that 20.6 percent of child workers in Sarlahi reported to have back injury compared to none in Bhaktapur. The major injuries identified with brick work included cuts, bruises, crushing of body parts, upper and lower limbs pains and back problems. The exposure to constant repetitive works had culminated to experiences of acute bodily pains in working children. The severity of pain was reported to be very bad by close to 11 per cent of workers in Bhaktapur while 20 per cent and 18 per cent of workers responded pain to be of medium grade in Bhaktapur and Sarlahi.

\section{Table II History of injury among child worker in last 1 year}

\begin{tabular}{|c|c|c|c|c|}
\hline \multirow{3}{*}{ Variables } & \multicolumn{2}{|c|}{ Bhaktapur } & \multicolumn{2}{|c|}{ Sarlahi } \\
\hline & $\begin{array}{c}\text { Case } \\
(\mathrm{N}=101)\end{array}$ & $\begin{array}{l}\text { Control } \\
(\mathrm{N}=64)\end{array}$ & $\begin{array}{l}\text { Case } \\
(\mathrm{N}=97)\end{array}$ & $\begin{array}{l}\text { Control } \\
(\mathrm{N}=43)\end{array}$ \\
\hline & \multicolumn{2}{|c|}{$\begin{array}{l}\text { Number }(\%) n \text { the } \\
\text { control group of } \\
\text { Bhaktapur. }\end{array}$} & \multicolumn{2}{|c|}{ Number (\%) } \\
\hline \multicolumn{5}{|c|}{ Any part of body injured } \\
\hline Yes & $\begin{array}{c}42 \\
(41.6)\end{array}$ & 19(29.7) & $\begin{array}{c}39 \\
(40.2)\end{array}$ & $13(30.2)$ \\
\hline No & $\begin{array}{c}59 \\
(58.4)\end{array}$ & $45(70.3)$ & $\begin{array}{c}59 \\
(58.4)\end{array}$ & $30(69.8)$ \\
\hline \multicolumn{5}{|c|}{ Parts of body injured (Multiple Response) } \\
\hline Leg or Foot & $\begin{array}{c}22 \\
(21.8)\end{array}$ & $5(7.8)$ & $\begin{array}{c}31 \\
(32.0)\end{array}$ & 10(23.3) \\
\hline Arm or hand & $\begin{array}{c}19 \\
(18.8)\end{array}$ & $12(18.8)$ & $\begin{array}{c}24 \\
(24.7)\end{array}$ & $4(9.3)$ \\
\hline Head & $5(5.0)$ & $1(1.6)$ & $2(2.1)$ & $3(7.0)$ \\
\hline Neck & $1(1.0)$ & $1(1.6)$ & $\begin{array}{c}12(12 . \\
4)\end{array}$ & $1(2.3)$ \\
\hline Back & $0(0)$ & $0(0)$ & $\begin{array}{c}20 \\
(20.6)\end{array}$ & $3(7.0)$ \\
\hline Eye or Ears & 2(2. 0$)$ & $2(3.1)$ & $0(0)$ & $1(2.3)$ \\
\hline Abdomen & $5(5.0)$ & $1(1.6)$ & $0(0)$ & $1(2.3)$ \\
\hline Shoulder & $0(0)$ & $0(0)$ & $3(3.1)$ & $1(2.3)$ \\
\hline Нip & $0(0)$ & $0(0)$ & $0(0)$ & $1(2.3)$ \\
\hline
\end{tabular}

The administration of Standardized Nordic questionnaires as shown in table III for analysis of musculoskeletal symptoms to child workers suggested that musculoskeletal disorder related pain and discomfort was experienced by close to 73 per cent of cases in Bhaktapur and almost 58 per cent of case respondents in Sarlahi. The questions focused on intensity and level of pain, discomfort and ache to different body parts majorly shoulder, elbows, wrists, back, hips, thighs, knees and ankles. It was reported that most of the child worker facing pain and discomfort had recurrent episodes of pain and were suffering from discomfort during the same week of this study. More than 80 per cent of control groups at both the districts showed no sign of pain and discomfort as per the Standardized Nordic questionnaires inferring that most of the pains were attributed to work and working conditions.

There are no formal trainings on brick making as mostly it is based on learning by doing approach. It was found that most of the children were involved in all brick making process except furnace works. The children reported that more than half of the 
respondents in Sarlahi (52.1 per cent) believed that they did not have adequate skills for the job they were performing, while only 7.6 per cent in Bhaktapur were confident with their skills. Only 3.3 per cent of respondents in Bhaktapur and 6.2 per cent in Sarlahi considered to have mastered skills for the job at hand. It was found that 42.4 per cent in Bhaktapur and 34.4 per cent in Sarlahi considered of having few skills for the brick making job.

Table III Nordic Ergonomic Questions result on Pain and Discomfort

\begin{tabular}{|c|c|c|c|c|}
\hline & \multicolumn{2}{|c|}{ Bhaktapur } & \multicolumn{2}{c|}{ Sarlahi } \\
\hline $\begin{array}{c}\text { Had trouble (ache, pain, } \\
\text { discomfort) }\end{array}$ & $\begin{array}{c}\text { Case } \\
(\mathrm{N}=101)\end{array}$ & $\begin{array}{c}\text { Control } \\
(\mathrm{N}=64)\end{array}$ & $\begin{array}{c}\text { Case } \\
(\mathrm{N}=85)^{\mathrm{a}}\end{array}$ & $\begin{array}{c}\text { Control } \\
(\mathrm{N}=43)\end{array}$ \\
\hline Yes & $73(72.3)$ & $12(18.8)$ & $49(57.6)$ & $7(16.3)$ \\
\hline No & $28(27.7)$ & $52(81.3)$ & $36(42.6)$ & $36(83.7)$ \\
\hline
\end{tabular}

a. Missing values were excluded from analysis

Table IV Pain experienced in different body parts

\begin{tabular}{|c|c|c|c|c|}
\hline \multirow{2}{*}{$\begin{array}{c}\text { Parts of body where } \\
\text { the respondents had } \\
\text { pain }\end{array}$} & $\begin{array}{c}\text { Case } \\
(\mathrm{N}=73)\end{array}$ & $\begin{array}{c}\text { Control } \\
(\mathrm{N}=12)\end{array}$ & $\begin{array}{c}\text { Case } \\
(\mathrm{N}=49)\end{array}$ & $\begin{array}{c}\text { Control } \\
(\mathrm{N}=7)\end{array}$ \\
\cline { 2 - 6 } & $\begin{array}{c}\text { Number } \\
(\%)\end{array}$ & $\begin{array}{c}\text { Number } \\
(\%)\end{array}$ & $\begin{array}{c}\text { Number } \\
(\%)\end{array}$ & $\begin{array}{c}\text { Number } \\
(\%)\end{array}$ \\
\hline Neck & $38(52.1)$ & $3(4.7)$ & $22(44.9)$ & $2(4.7)$ \\
\hline Shoulders & $31(42.5)$ & $1(1.6)$ & $19(19.6)$ & $1(14.3)$ \\
\hline Elbows & $25(34.2)$ & $2(3.1)$ & $16(33.1)$ & $2(28.6)$ \\
\hline Wrists/hands & $28(38.4)$ & $2(3.1)$ & $17(34.2)$ & $2(28.6)$ \\
\hline Upper back & $40(54.8)$ & $9(75.0)$ & $4(8.2)$ & $6(85.7)$ \\
\hline Lower back & $40(54.8)$ & $0(0)$ & $5(10.2)$ & $0(0)$ \\
\hline Hips/thighs & $37(50.7)$ & $5(41.7)$ & $16(41.7)$ & $3(42.9)$ \\
\hline Ankles/feet & $44(60.3)$ & $0(0)$ & $22(57.9)$ & $0(0)$ \\
\hline Knees & $45(68.2)$ & $0(0)$ & $16(69.2)$ & $0(0)$ \\
\hline
\end{tabular}

The table IV above shows respondents reporting pain in different body parts. This is an exclusive list incorporating only respondents reported to have undergone pain. It was found that single respondent reported to have undergone multiple pains. It was identified that pain were mostly confided to limbs, neck and back. Closer to 72 per cent of case respondents in Bhaktapur and almost 50 per cent in Sarlahi reported to have undergone pain related to musculoskeletal problems. 45 cases in Bhaktapur reported to have pain in knees and 40 each for upper and lower back pain. 33 per cent and 34 per cent of cases in Sarlahi reported to have pain in elbow and wrist. Only 18 per cent of control in Bhaktapur and 16 per cent in Sarlahi reported to have musculoskeletal problems.
The table $\mathrm{V}$ below shows the odds ratio presenting association of pain among working children (cases) compared to non-working children (controls).

Table V Pain experienced in different body parts

\begin{tabular}{|c|c|c|c|}
\hline & Yes $^{b}$ & No & Odds Ratio \\
\hline \multicolumn{4}{|c|}{ Experience of any trouble in last one year } \\
\hline Cases & 122 & 64 & $8.82(4.93 ; 15.78)^{\#}$ \\
\hline Controls & 19 & 88 & 1 \\
\hline \multicolumn{4}{|l|}{ Pain in Neck ${ }^{c}$} \\
\hline Cases & 60 & 62 & $2.70(0.92 ; 7.98)$ \\
\hline Controls & 5 & 14 & 1 \\
\hline \multicolumn{4}{|c|}{ Pain in Shoulders ${ }^{c}$} \\
\hline Cases & 50 & 72 & $5.93(1.30 ; 26.69)^{\#}$ \\
\hline Controls & 2 & 17 & 1 \\
\hline \multicolumn{4}{|l|}{ Pain in Elbow ${ }^{c}$} \\
\hline Cases & 58 & 64 & $3.39(1.06 ; 10.82)^{\#}$ \\
\hline Controls & 4 & 15 & 1 \\
\hline \multicolumn{4}{|c|}{ Pain in Upper back ${ }^{c}$} \\
\hline Cases & 44 & 78 & $0.15\left((.05 ; 0.48)^{\#}\right.$ \\
\hline Controls & 15 & 4 & 1 \\
\hline \multicolumn{4}{|c|}{ Pain in Hips/Thighs ${ }^{b}$} \\
\hline Cases & 53 & 59 & $1.23(0.46 ; 3.30)$ \\
\hline Controls & 8 & 11 & 1 \\
\hline
\end{tabular}

The odds ratio suggests that working children were 8 times more likely to experience trouble or body pain compared to non-working children. Neck pain, shoulder pain and elbow pain are positively associated to working children and the association was significant at $5 \%$ level of significance $(p<0.05)$.

\section{Discussion}

The study showed that musculoskeletal injuries and problems exist as a major threat in the brick industries of Nepal. The association of children in hazardous works in absence of any safe practices and management has increased this risk to manifolds. The comparison of working and non-working children also revealed the vulnerabilities of children exposed to brick manufacturing with prevalent musculoskeletal injuries and problems attributed to work.

The physical factors and external ambient environment for the brick making job were found to be with full of risks. Brick workers, especially molders, were exposed to the heat and natural conditions for longer duration; additionally the workers are also exposed to high concentrations of dust, fumes and particulate. The incidences of Work Related Musculoskeletal Disorders (WMSDs) were quite common in the brick industries. Research in manual brick industries have revealed that longer 
standing hours, continued deviated wrist positions and forceful exertions has increased risk of work related musculoskeletal disorders [17] which also remains valid for this study. The presence of fall and drowning risks were also high as workers were exposed to conditions with heavy load and unsafe surrounding e.g. with presence of open pits and water holes. Jobs in brick kilns involve a wide range of physical actions demanding different postures and positions which are not often considered to be ideal increasing more risks of accidents and injuries. The common jobs in brick kilns often comprises of pushing, pulling, bending, reaching, stretching, lifting, lowering, sitting, standing, walking and carrying, mining/rimming of clay, preparation of clay, molding of clay, drying of bricks and burning of bricks. Although mechanized process was found to be used in some kilns physical forces dominates this sector with increasing physical discomforts. The prolonged stresses and strains caused during various activities with different load conditions in the brick industries can be the major cause for work related musculoskeletal disorders [2]. Kopf et al. (1988) reported in a similar line to this study finding that with increasing levels of job demands aggravated by heavy physical work, awkward postures, repetitive and continuous movement and restrictive positions attributes to exposure response relationship between sickness and forceful, repetitive work [18].

The World Health Organization, recognizing the impact of work-related musculoskeletal diseases, has characterized work related musculoskeletal disorder as multifactorial, indicating that a number of risk factors contribute to and exacerbates these maladies [19]. As evident with study findings based on environmental setting, injury history and work practice various risk factors compounds to musculoskeletal disorders. The common reported disorder related to musculoskeletal involves majorly injury of the soft tissues are referred to by many names, including WMSDs, repetitive strain injuries (RSI), repetitive motion injuries (RMI), and cumulative trauma disorders (CTDs) around the globe [20]. A comprehensive review of epidemiological studies has assessed the risk factors associated and has categorized work related musculoskeletal disorder affecting the body part including (1) neck and neck-shoulder, (2) shoulder, (3) elbow, (4) hand-wrist, and (5) back which are often attributed to task-related risk factors including repetition, force, posture, vibration, temperature extremes, and static posture [21]. The similar risk factors and resulting body discomfort were also identified in the sampled kilns of Nepal.

The postures adopted by the workers depends largely upon nature of work, the design and environment of the work place, personal characteristics of individual worker, the tools used for work and also on the duration and frequency of the work cycle [22]. The posture required for brick making job varies according to the job, letting aside the mechanized process, the manual conditions for soil excavation, kneading and molding process requires constant movement and transfer of heavy loads. The molding job which is considered to be the most difficult job requires remaining in squatted position for longer duration with constant upper limb movement under natural environment exposure. The musculoskeletal disorders were also found to be compounded with lifting of heavy loads. Most of the loads were found to be carried in back or in head with higher chances of injuries to back, neck and shoulders.

The vulnerability of children with exposure to unsafe working conditions and missing ergonomics practices pose considerable risk to their physical well-being. The fragility of children and their susceptibility owing to their tender age makes children more prone to work related problems. This study showed that children responded to multiple pain and injuries owing to working conditions. It has been identified that children are more prone to musculoskeletal disorders and varieties of work related problems including injuries and illness. The little experience at work, developing physique and little awareness on work risks has increased greater chances of illness among children [23]. The associated risk involved for children were identified as heat syndromes; joint and bone deformities; musculoskeletal problems from repetitive motion; blistered hands; bruised feet from dropped bricks; lacerations; breathing difficulties; silicosis and other occupational lung diseases; insect bites; poor nutrition; bacterial and viral diseases; and injury from moving vehicles as the major health impacts from the brick industry [24] which also corroborates with this research findings.

The burden of child labor is not a new phenomenon in Nepal. Although poverty remains as the major push factor for children to start working in the kilns but lack of awareness and feeble enforcement of legal tools remains major factors contributing children to work at the kilns. Research accords to this study findings that child labor does not replace adult labor, but complements it [25], similar to this study which identified that children were mostly accompanying their parents to work at the brick kilns.

The optimal use of ergonomics can considerably reduce work related risks and increase overall well-being of productive worker. The primary objective of ergonomics is to minimize the risk of work-related musculoskeletal disorders through planning, designing, assessing and evaluating tasks, jobs, tools and systems [26]. The objectives are achievable but preparedness and commitment is imperative at all levels. This study was based on handful sample nevertheless it portrays an overview of musculoskeletal disorders in the brick kilns focusing on child labors. Future studies are required to explore more on both clinical and non-clinical parameter affecting musculoskeletal problems, furthermore policy analysis endeavors would also help reduce risks and establish safe practices.

\section{Conclusion}

The musculoskeletal disorders and injuries related to brick manufacturing were highly present in the sampled brick industries. The children with exposure to unsafe working conditions were found more vulnerable to injuries. The comparison among working and non-working children also showed ample evidence of musculoskeletal injuries related to 
works. The ergonomics and safe practices have to be established to reduce work related vulnerabilities and increasing over all wellbeing of workers. Although the concept of safety/ health and good ergonomics practices are still missing in the brick kilns of Nepal awareness on these are absolute for required changes. The major issue of child labor remains a cross cutting issues which requires serious efforts and contribution of all involved. This study has been able to identify that musculoskeletal disorders and injuries remains prevalent in brick kilns of Nepal and catering physical, organizational and cognitive ergonomics needs will ensure good work practices and better health of workers.

\section{Acknowledgement}

This study has been supported by the International Labor Organization and World Education Inc.

\section{References}

1. Bernard, B.P. Musculoskeletal Disorders and Workplace Factors, A Critical Review of Epidemiologic Evidence for Work-Related Musculoskeletal Disorders of the Neck, Upper Extremity, and Low Back, U.S. Department of Health and Human Services, DHHS (NIOSH), 1997, Publication No. 97B141

2. Nepal Environmental \& Scientific Services (1994). Assessment of the Applicability of Indian Cleaner Process Technology for Small Scale Brick Industries of Kathmandu Valley, Metropolitan Environment Improvement Programme, Kathmandu.

3. Pope CA et al. Lung cancer, cardiopulmonary mortality, and long-term exposure to fine particulate air pollution. Journal of the American Medical Association, 2002; 287:1132- 1141. http://dx.doi.org/10.1001/jama.287.9.1132

4. Schwartz J. Air pollution and hospital admissions for respiratory disease. Epidemiology, 1996; 7(1): 20-28. http://dx.doi.org/10.1097/00001648-199601000-00005

5. Pope CA, Dockery DW. Acute health effects of PM10 pollution on symptomatic and asymptomatic children. The American review of respiratory disease, 1992; 145: 11231128. http://dx.doi.org/10.1164/ajrccm/145.5.1123

6. Donaldson $K$. et al. Ambient particle inhalation and the cardiovascular system: potential mechanisms. Environmental health perspectives, 2001; 109(Suppl 4): 523 $-527$.

7. Bobak M. Outdoor air pollution, low birth weight, and prematurity. Environmental health perspectives, 2000; 108: 173176. $h$ ttp://dx.doi.org/10.1289/ehp.00108173

8. Chaudhary, S.S., Biswas, C., Roy, K., (2012), A Subjective and Objective Analysis of Pain in Female Brick Kiln Worker of West Bengal, International Journal of Occupational Safety and Health, 2012; 2 (2): 38-43.

9. Qutubuddin S.M., Hebbal, S. S., \& A.C. S. Kumar. Ergonomic Evaluation of Tasks Performed by Workers in Manual Brick Kilns in Karnataka, India. Global Journal of Researches in Engineering, 2013; 13(4): Version 1.0
10. SEED Nepal, Report on Identification and Analysis of hazardous and Risky Works in Brick Manufacturing Industries of Nepal. 2013, Occupational Safety and Health Project: Anamnagar, Kathmandu, Nepal.

11. Manoharan, P.K., B.K. Singh, and S.K. Jha, Ergonomics investigation using Psycho-physiological study for brick kilns' in Jharkhand. Int J Environ Sci, 2012; 2(3): 14841491.

12. Sahu, S., M. Sett, and S. Gangopadhyay, An ergonomic study on teenage girls working in the manual brick manufacturing units in the unorganized sectors in West Bengal, India. J Hum Ergol (Tokyo), 2010; 39(1): 35-44.

13. Mukhopadhyay, P. Risk Factors in Manual Brick Manufacturing in India. Ergonomics Australia, 2008; 22 (1):16-25

14. CBS. Population Census 2001. Kathmandu: Central Bureau of Statistics.

15. Plan International and world education (2012). A Rapid Assessment of Children in the Brick Industry: Kathmandu.

16. Kuorinka I, Jonsson B, Kilbom A, Vinterberg $H$, BieringSorensen F, Andersson G, Jorgensen K: Standardised Nordic questionnaires for the analysis of musculoskeletal symptoms. Appl Ergon, 1987; 18(3):233-237. http://dx.doi.org/10.1016/0003-6870(87)90010-X

17. Trevelyan, FC and Haslam, RA. Musculoskeletal Disorders in a Handmade Brick Manufacturing Plant, International Journal of Industrial Ergonomics, 2001; 27(3):43-55 http://dx.doi.org/10.1016/S0169-8141(00)00036-6

18. Kopf T, Von Feder T, Karmaus W. Risks for musculoskeletal disorders of the low back, the shoulders, the elbows, and the wrists in bricklayers. In: Hogstedt C, Reuterwall C, R-17 eds. Progress in occupational epidemiology. Amsterdam: Elsevier Science Publishers B.V., 1998:219-222.

19. Sauter, S., Hales, T., Bernard, B., Fine, L, Petersen, M., Putz-Anderson, V., Schleiffer, L., Ochs, T. Summary of two NIOSH field studies of musculoskeletal disorders and VDT work among telecommunications and newspaper workers. In: Luczak, H., Cakir, A. \& Cakir, G. (Eds.). Elsevier Science Publishers, B.V., 1993.

20. McCauley Bush, P. Ergonomics: Foundational Principles, Applications and Technologies, an Ergonomics Textbook; CRC Press, Taylor \& Francis, Boca Raton, FL, 2011.

21. NIOSH (1997). Musculoskeletal Disorders and Workplace Factors, NIOSH Publication No. 97-141, http://www.cdc.gov/niosh/docs/97-141

22. R. S. Bridger, Introduction to Ergonomics, McGraw-Hill Higher Education,1995, ISBN 007007741X, 9780070077416 http://dx.doi.org/10.4324/9780203426135

23. World Vision, Child Workers in Brick Factories: Causes and Consequences, A Research Study for Campaign of Combating the Worst Forms of Child Labor, Phnom Penh, Cambodia, 2007.

24. ILO, Children in hazardous work- What we know- What we need to do, International Programme on the Elimination of Child Labor (IPEC), Geneva, Switzerland, 2011.

25. Grimsrud B. Millennium Development Goals and Child Labour, Understanding Children's Work an Inter Agency Research Cooperation project, 2003. ILO, UNECEF and World Bank Group Project. Available at : http:// www.ucw.un.org/esa/socdev/rwss/docs/2007/biblio.pdf

26. Berrigan. J. Ergonomics. Environmental/Occupational Health \& Safety Office. Retrieved from http://www.wlu.ca/ documents/42148/Ergonomics.pdf on February 06. 2013 